\title{
Model Solving of Aluminium Alloy Solidification
}

Tereza Jarosova (0000-0002-3651-5079), Blanka Skocilasova (0000-0001-8242-3231), Frantisek Klimenda (00000001-7937-3755), Jan Sterba (0000-0002-2676-3562), Vit Cernohlavek (0000-0001-6816-1124)

Faculty of Mechanical Engineering, Jan Evangelista Purkyne University in Usti nad Labem. Pasteurova 3334/7, 40001 Usti nad Labem. Czech Republic. E-mail: tery.machacha@seznam.cz, blanka.skocilasova@ujep.cz, frantisek.klimenda@ujep.cz, jan.sterba@ujep.cz, cernohlavek@ujep.cz

The paper deals with the process of solidification of a cast aluminium piston into a metal mould (mould). The introductory part presents the methodology of solution where the physical properties of both the aluminium alloy and the steel mould are presented. Furthermore, the solution itself is described, which is performed on one quarter the size of a piston model by using FEM in the ANSYS FLUENT program. Piston solidification temperatures were recorded every five minutes due to the solution complexity. Next part of the paper presents the evaluation where temperature sections in two mutually perpendicular planes and a quarter a size 3D model of piston solidification are presented. At the end of the paper, an overall evaluation of the thermal solidification of the cast piston depending on the solidification time is performed. The results of the numerical solution show that the solidification process begins at 2.5 minutes after casting and ends at 5 minutes. Subsequently, only the piston and the metal mould itself are cooled.

Keywords: crystallization, aluminium alloy, mould, gravity casting, FEM

\section{Introduction}

Foundry is one of the oldest, most evolving and most frequently used technologies and as such it represents the most economical transformation of a starting material into a finished product or semi-finished product. Depending on the requirements for the properties of materials, foundry has developed both in the use of casting technology and in the use of alloys [1].

In practice, gravity casting of pistons into metal moulds is carried out by heating the aluminium alloy to approximately $800{ }^{\circ} \mathrm{C}$ before casting. The casting itself takes place at a temperature of $750-780^{\circ} \mathrm{C}$. The mould is heated by flame burners to $150-200^{\circ} \mathrm{C}$. The core in the mould is also heated. Both mould and core are made of steel. In industrial conditions, the casting process takes approximately 2-4 seconds, depending on the size of the casting. The mould opens after approximately 60 seconds and the casting is removed. The mould and cores are water-cooled.

\section{Aluminium alloy solidifiction mechanism}

As any solution solidifies, including metals, crystallization occurs. Crystallization is the process by which metals and alloys pass from a liquid state to a solid state. This process has a significant effect on the resulting structure of the casting and its mechanical properties. The crystallization process depends on the rate of formation of crystallization nuclei and on the linear rate of their growth. The condition for the smo- oth course of crystallization within the thermodynamic system is the thermodynamic stability of the resulting phase, which must have a smaller free enthalpy than the original phase. The fine-grained structure of castings is formed at a high rate of formation of crystallization nuclei and a low linear rate of their growth. The condition for the crystallization of the melt to take place is a sufficiently large supercooling of the melt.

Only melt occurs above the liquidus curve. Upon gradual cooling below the liquidus temperature, the crystallization process begins in the material. Crystallization ends on the solid curve, below this curve there is only a solid phase. Between the liquid and the solid there are crystals of the solid phase and the liquid phase of the melt.

\section{Crystallization}

Crystallization in the melt begins with so-called nucleation. Nucleation is a process in the melt during which a cluster of atoms is formed that are crystalline. They are the so-called "crystallization nuclei". Crystallization nuclei are formed when the temperature drops below the freezing point. Nucleation can be homogeneous and heterogeneous. Homogeneous nucleation means that nuclei are formed in pure metal, but under normal conditions heterogeneous nucleation occurs, which is caused by the presence of foreign particles (mold parts, particles of foreign solid phases, inoculants, alloy modifiers, etc.)

After the formation of nuclei, the second phase of solidification occurs and that is the growth of crystals. 
The crystals do not grow uniformly from the nucleus, but the growth is concentrated only in certain crystallographic directions. Crystals form in the primary, secondary and tertiary axes and thus resemble a tree or fern in appearance. This crystal formation is called a dendrite. The size, direction and degree of growth of the dendrite depends on the content of soluble and insoluble impurities and on the direction and rate of cooling.

If the heat is dissipated more intensively in one direction, oriented grains with a columnar structure are formed. In this case, there is a danger that if the dendrite transversely fills a substantial part or the entire casting, an unsatisfactory structure will be formed. The phenomenon when the dendrite grows in the cross section of the whole casting is called transcrystallization. This phenomenon is undesirable, the casting can no longer be processed. The aim is to enable uniform cooling of the casting, the dendrite is then uniform and forms a polygon, in the best case the shape of the grain forms a hexagon. Fine and branched dendrites are formed at high cooling rates. If the cooling rate and the content of impurities decrease, the internal structure in the dendrite coarsens and globulite is formed.

Other publications that deal with the problem of
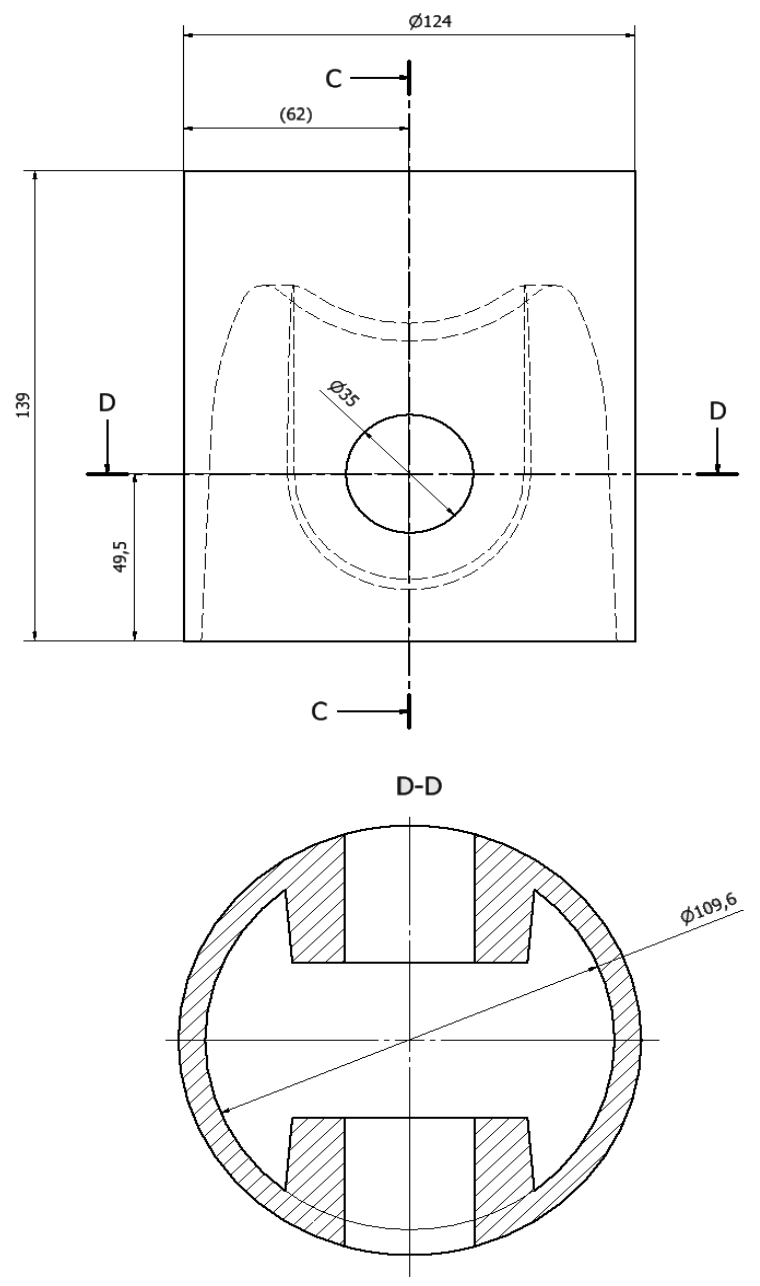

properties of aluminum alloys by experimental or numerical solutions are: Influence of heat treatment on the change of properties of $\mathrm{Al}-\mathrm{Si}$ coating in sheets with very high strength. [12], Analysis of Microstructure Changes for AlSi7Mg0.3 Alloy Caused by Modification [13], Monitoring the fatique crack on the test specimen during the cyclic loading [14], Effect of Wall Thickness on the Quality of Casts from Secondary Aluminium Alloy [15].

\section{Methodology of solution}

In this model case of piston solidification, the ingot mould was heated to $200^{\circ} \mathrm{C}$, but it was not cooled and solidification in the mould occurred spontaneously. For this reason, the monitoring time interval was selected to be one hour. The simulation starts at time 0 , when the alloy had a temperature of $800^{\circ} \mathrm{C}$. The piston solidification simulation was performed in the ANSYS Fluent program, version 15.0, and images from this program are displayed after five minutes.

The solution was started by creating a drawing of the idealized piston Fig. 1. Furthermore, a network was created for casting a piston, which is made of aluminum alloy, defined by the program ansys fluent, and molds. The drawings were transferred to Ansys Fluent, then a quarter model was created.

\section{C-C}

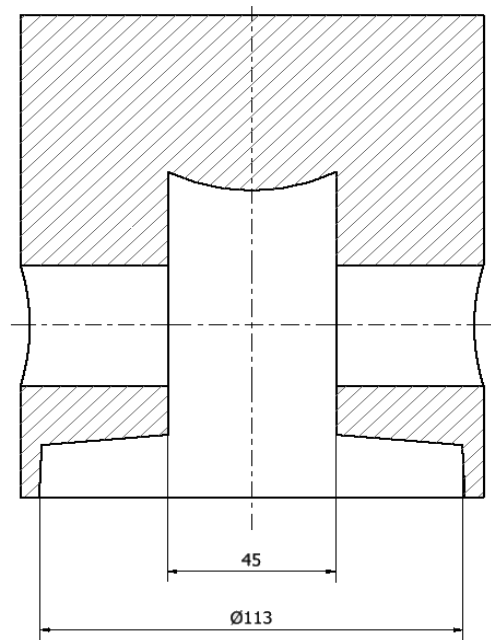

Fig. 1. Piston model 
The basic physical properties of the mould and the cast aluminium alloy are given in Tab.1 and Tab. 2.

Tab. 1 Physical properties of steel mould [11]

\begin{tabular}{|c|c|c|}
\hline Quantity & Value & Unit \\
\hline Density & 7850 & $\mathrm{~kg} \cdot \mathrm{m}^{-3}$ \\
\hline Thermal conductivity & 45 & $\mathrm{~W} \cdot \mathrm{m}^{-1} \cdot \mathrm{K}^{-1}$ \\
\hline Specific heat capacity & 540 & $\mathrm{~kJ} \cdot \mathrm{kg}^{-1} \cdot \mathrm{K}^{-1}$ \\
\hline
\end{tabular}

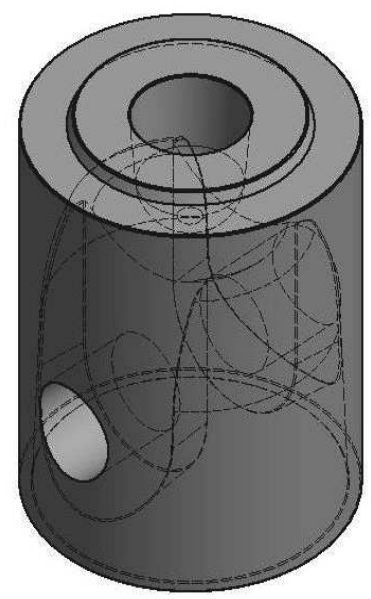

Fig. 2 3D piston model

Tab. 2 Physical properties of aluminium alloy [9]

\begin{tabular}{|c|c|c|}
\hline Quantity & Value & Unit \\
\hline Density & 2730 & $\mathrm{~kg} \cdot \mathrm{m}^{-3}$ \\
\hline Boiling point & 2494 & ${ }^{\circ} \mathrm{C}$ \\
\hline Liquidus temperature & 660 & ${ }^{\circ} \mathrm{C}$ \\
\hline Solidus temperature & 550 & ${ }^{\circ} \mathrm{C}$ \\
\hline Casting temperature & 800 & ${ }^{\circ} \mathrm{C}$ \\
\hline $\begin{array}{c}\text { Thermal conductivity } \\
\text { at } 25{ }^{\circ} \mathrm{C}\end{array}$ & 247 & $\mathrm{~kJ} \cdot \mathrm{kg}^{-1} \cdot \mathrm{K}^{-1}$ \\
\hline $\begin{array}{c}\text { Specific heat capacity at } \\
25{ }^{\circ} \mathrm{C}\end{array}$ & 0.9 & $\mathrm{~kJ} \cdot \mathrm{kg}^{-1} \cdot \mathrm{K}^{-1}$ \\
\hline $\begin{array}{c}\text { Specific heat capacity at } \\
660{ }^{\circ} \mathrm{C}\end{array}$ & 1.18 & $\mathrm{~kJ} \cdot \mathrm{kg}^{-1} \cdot \mathrm{K}^{-1}$ \\
\hline $\begin{array}{c}\text { Thermal expansion } \\
\text { Dynamic viscosity at } \\
750^{\circ} \mathrm{C}\end{array}$ & 27.4 & $\mu \mathrm{m} \cdot \mathrm{Kg}^{-1} \cdot \mathrm{K}^{-1}$ \\
\hline \begin{tabular}{c} 
Dhe \\
\hline
\end{tabular} & & $\mathrm{Pa}^{\circ} \cdot \mathrm{s}$ \\
\hline
\end{tabular}

The temperature $800{ }^{\circ} \mathrm{C}$ was used due to the smooth modeling in the ansys fluent program and was determined by experts in this program. In the same way, an alloy was determined, which is predefined in the
Ansys fluent program, the exact composition of which is not (in our case) essential for the simulation in this case.

A 3D piston model (Fig. 2) was created before the actual solution to the simulation and this piston was converted into the ANSYS Fluent program. Regarding the fact the piston was symmetrical in relation to both symmetry axes, only one quarter a size model was used, around which the quarter a size mould was modelled (Fig. 3). Subsequently, boundary conditions were inserted, including the material of the mould and piston, planes symmetry, temperatures, etc.

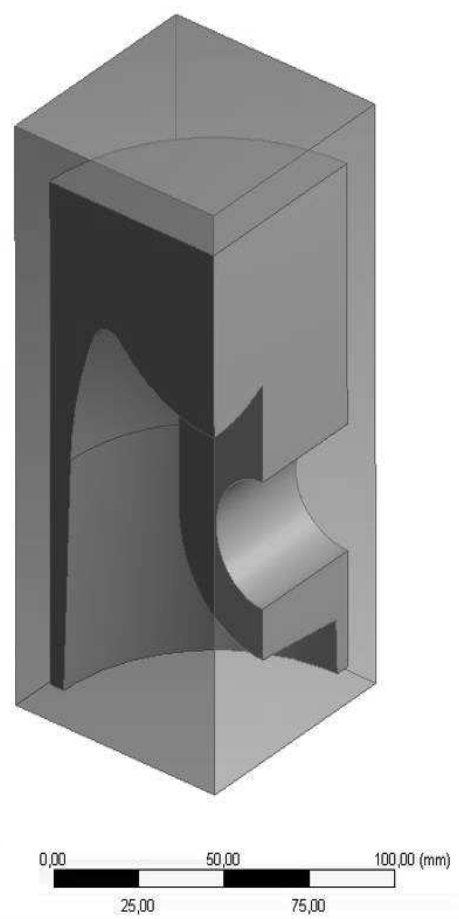

Fig. 3 Quarter a size piston model in the mould

After inserting boundary conditions, a network of piston and mould was formed. Both bodies were networked with tetrahedron triangular elements. The number of elements is given in tab. 3.

Tab. 3 Grid parameters

\begin{tabular}{|c|c|c|}
\hline Name & Number of nodes & $\begin{array}{c}\text { Number of ele- } \\
\text { ments }\end{array}$ \\
\hline Mould & 116.700 & 663.681 \\
\hline Piston & 31.364 & 171.988 \\
\hline Total number & 148.064 & 835.669 \\
\hline
\end{tabular}

The actual simulation took place at the Faculty of Mechanical Engineering at the University of Žilina. 


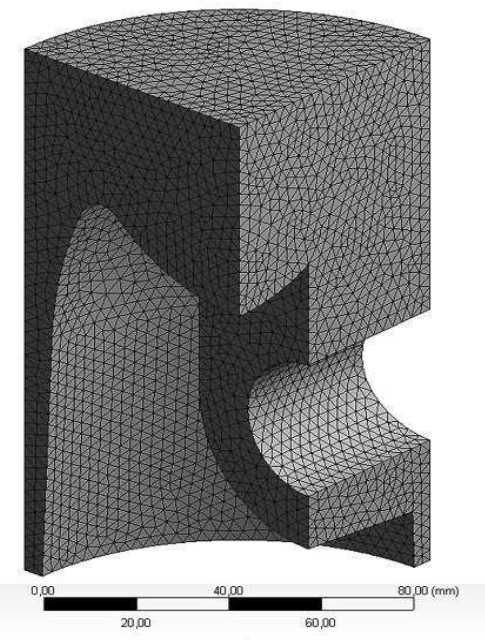

a)

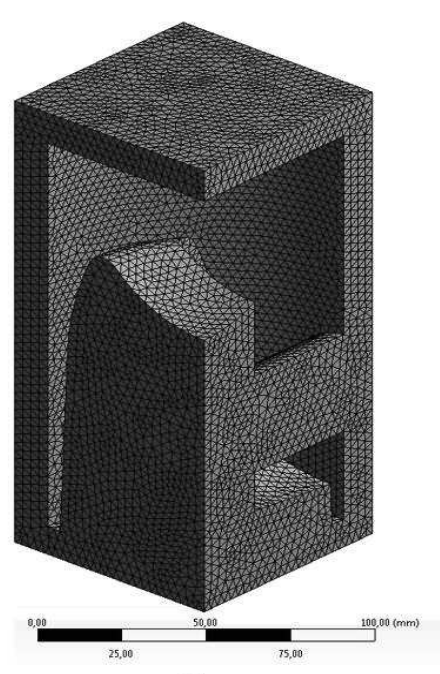

b)

Fig. 4 A quarter a size piston model with grid (a) mould model with grid (b)

\section{Evaluation}

The evaluation of the cooling simulation took place in two planes and for the whole quarter a size 3D piston model. Fig. 5 shows the planes in which the evaluation was carried out.

As stated in the previous chapter, at the time $\mathrm{t}=$ $0 \mathrm{~min}$ is the maximum temperature in the melt $800^{\circ} \mathrm{C}$ and the mould temperature is at $200{ }^{\circ} \mathrm{C}$, see Fig. 6 .

After ten minutes, the maximum temperature in the casting is at $421{ }^{\circ} \mathrm{C}$, see Fig. 7. During these first ten minutes, the temperature of the casting exceeds the liquidus temperature as well as the solidus temperature. The casting is solidified and during the following minutes we merely observe the cooling of the alloy.

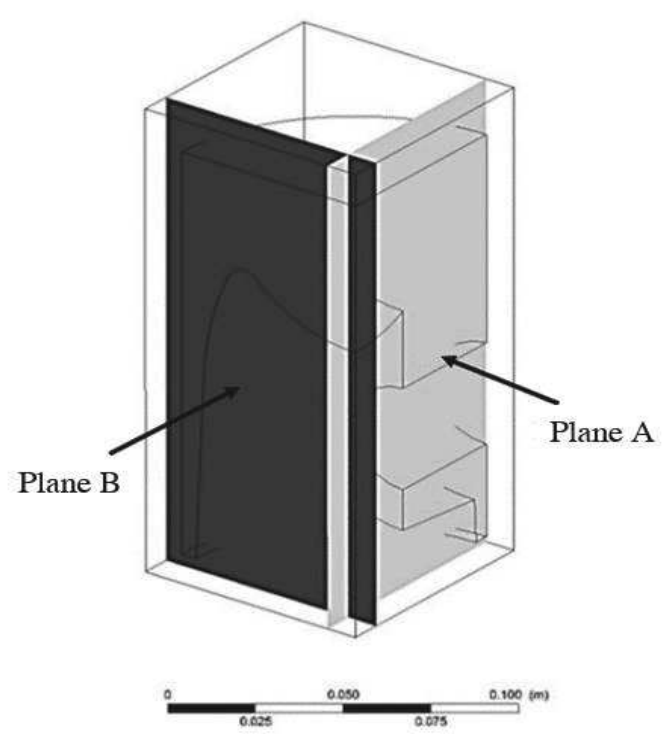

Fig. 5 Geometric sections for evaluation

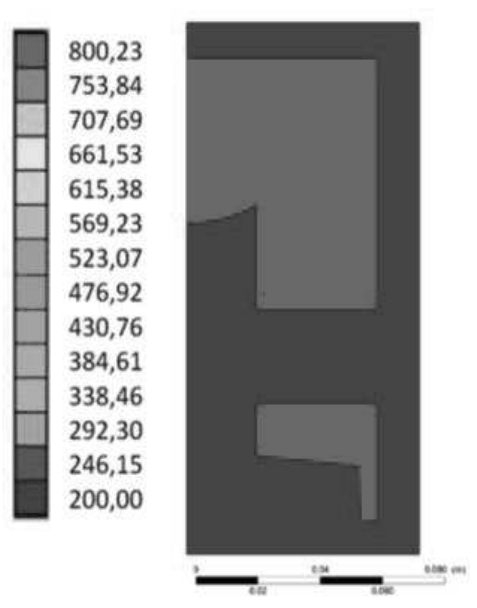

a)

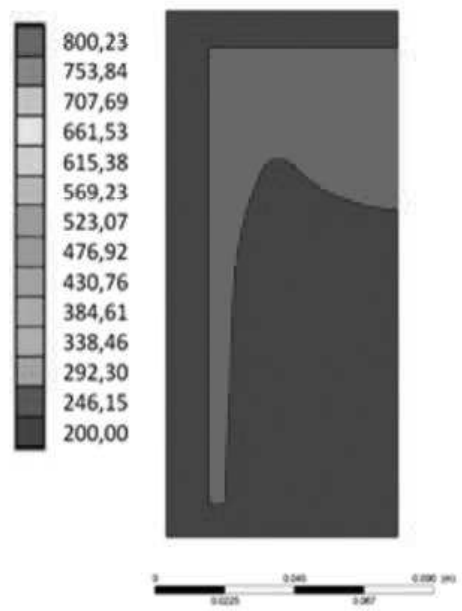

b)

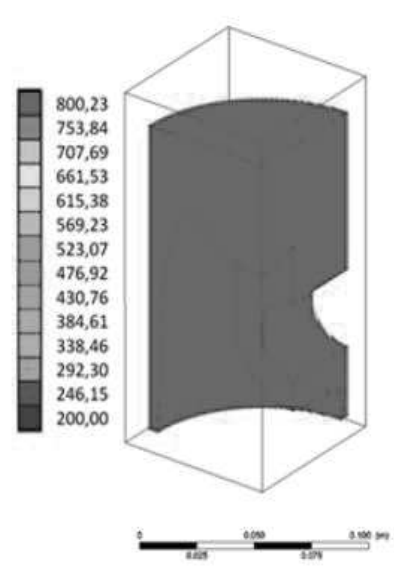

c)

Fig. 6 Temperature course at time $t=0$ min in section $A$ (a), in section B (b) $3 D$ piston model (c) 


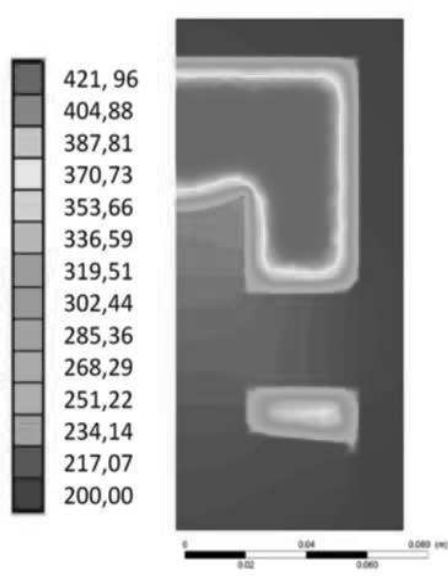

a)

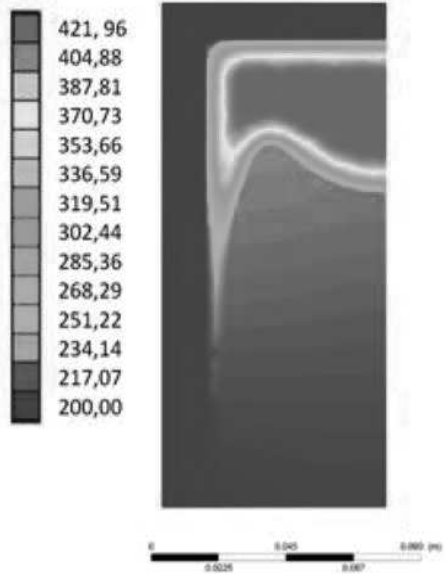

b)

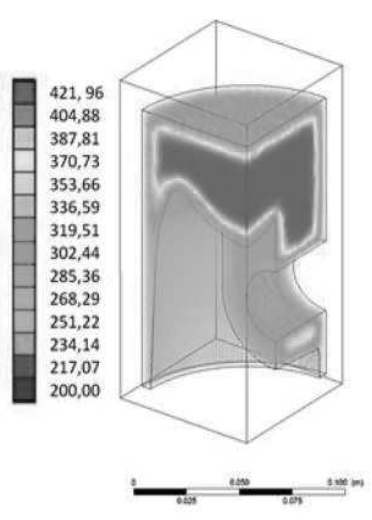

c)

Fig. 7 Temperature course at time $t=10$ min in section $A$ (a), in section B (b) $3 D$ piston model (c)

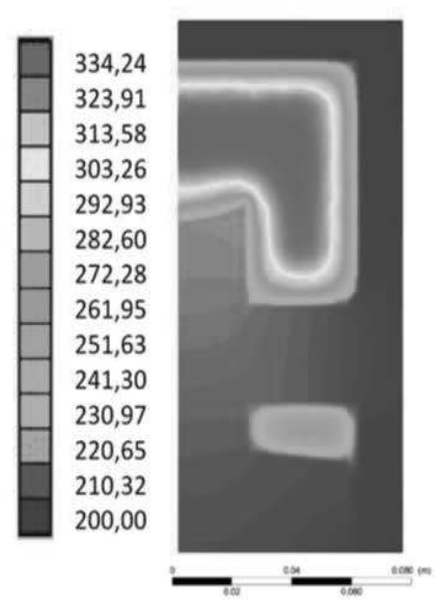

a)

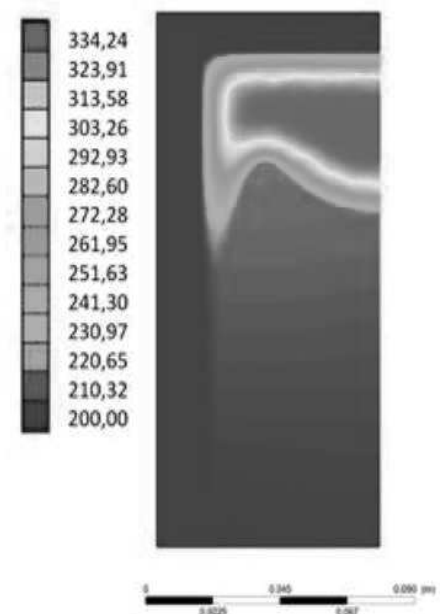

b)

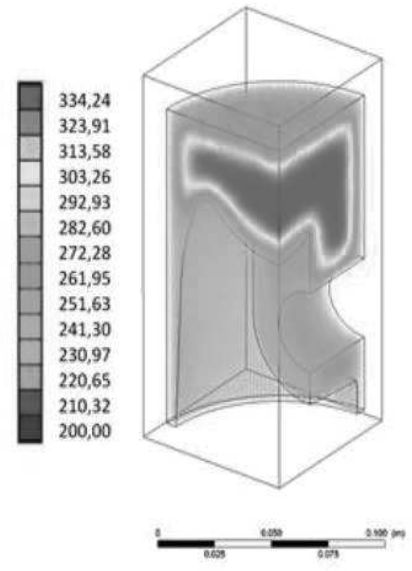

c)

Fig. 8 Temperature course at time $t=20$ min in section $A(a)$, in section $B$ (b) $3 D$ piston model (c)

At time $t=20 \mathrm{~min}$. is the highest temperature in the casting $334.24{ }^{\circ} \mathrm{C}$ - see Fig. 8

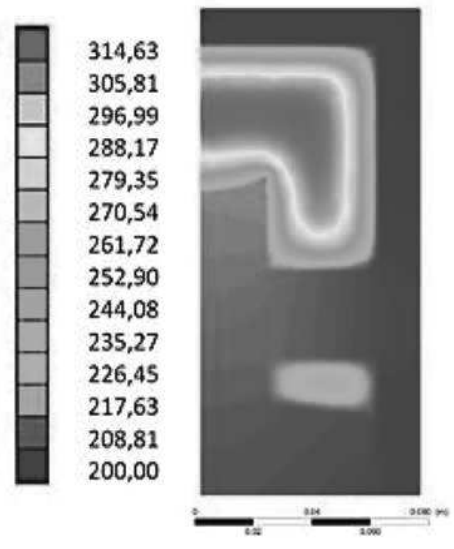

a)

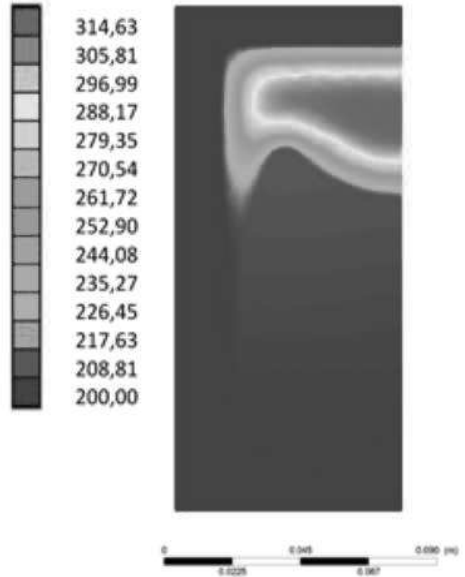

b)

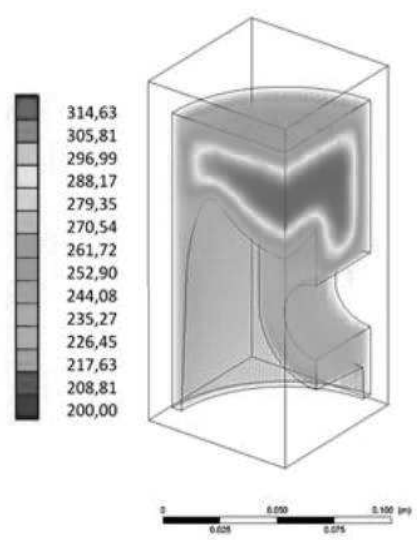

c)

Fig. 9 Temperature course at time $t=30$ min in section $A$ (a), in section B (b) $3 D$ piston model (c)

At time $t=30 \mathrm{~min}$. is the highest temperature in the casting $314.63{ }^{\circ} \mathrm{C}-$ see Fig. 9 . 


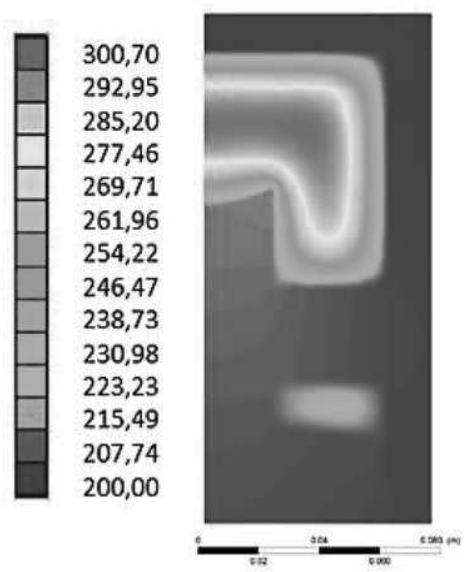

a)

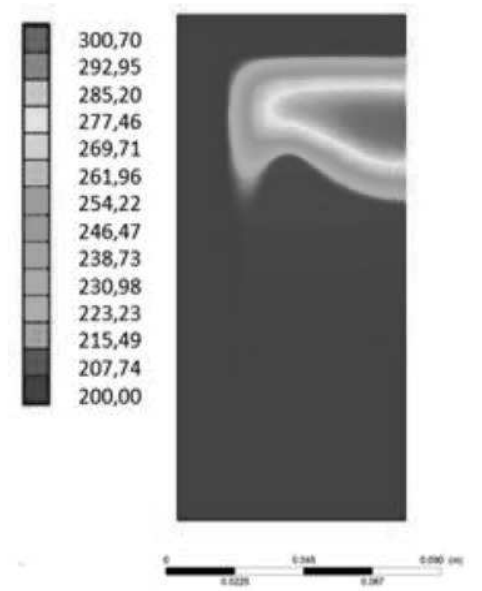

b)

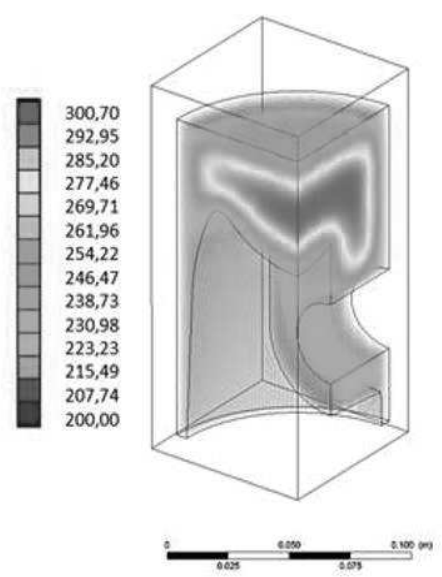

c)

Fig. 10 Temperature course at time $t=40$ min in section $A(a)$, in section B (b) $3 D$ piston model (c)

At time $t=40 \mathrm{~min}$. is the highest in the casting $300.7^{\circ} \mathrm{C}$ - see Fig. 10 .

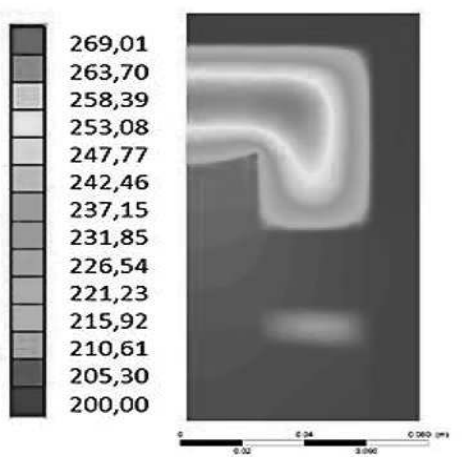

a)

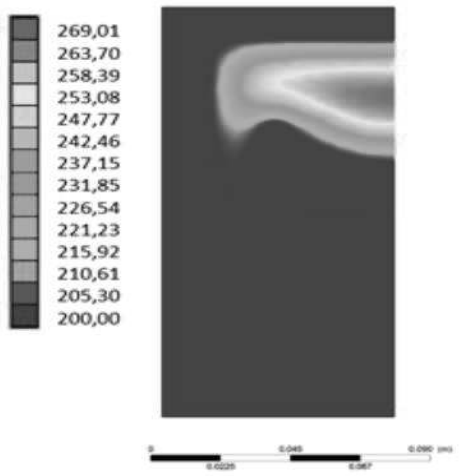

b)

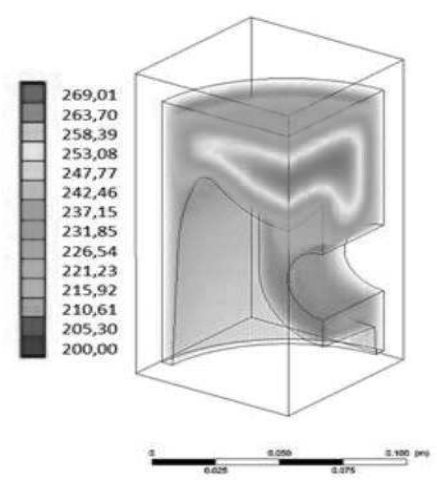

c)

Fig. 11 Temperature course at time $t=50$ min in section $A$ (a), in section B (b) $3 D$ piston model (c)

At time $t=50 \mathrm{~min}$. is the highest temperature in the centre of the piston $269.01{ }^{\circ} \mathrm{C}$ - see Fig. 11.

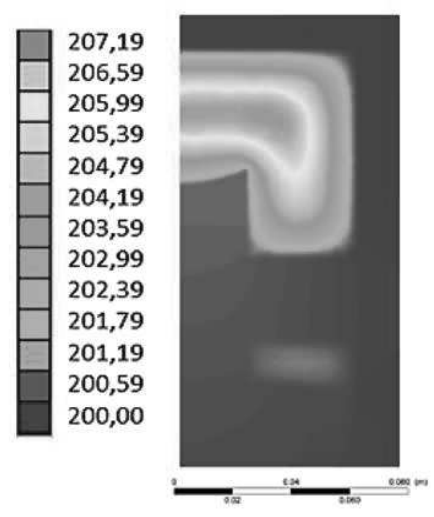

a)

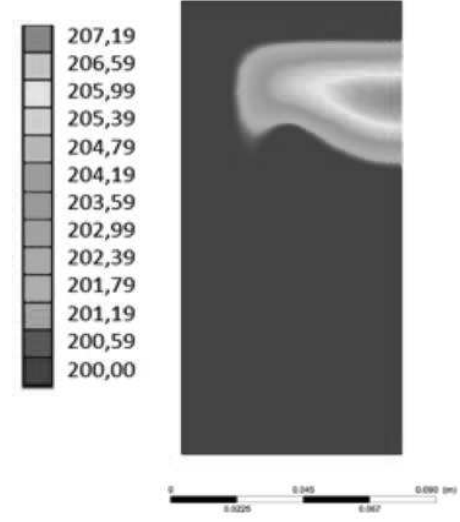

b)

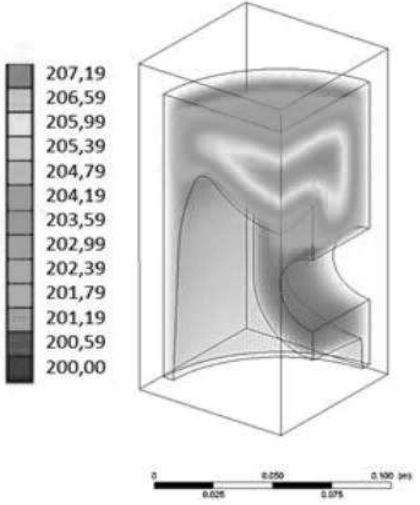

c)

Fig. 12 Temperature course at time $t=60$ min in section $A(a)$, in section $B$ (b) $3 D$ piston model (c)

After an hour of cooling down at time $\mathrm{t}=60 \mathrm{~min}$ is the highest temperature in the casting $207.19^{\circ} \mathrm{C}$ - see Fig. 12.

The results show that during the first ten minutes of the casting cooling, the melt temperature exceeds both the liquidus temperature and the solidus tempe- rature. The graph, which shows the course of temperatures in the horizon of one hour (Fig. 13), shows that the temperature of the alloy exceeds the liquidus temperature in 2.5 minutes and the solidus temperature in 5 minutes. The whole crystallization process lasted only 2.5 minutes and took place in the temperature range of 660 to $550{ }^{\circ} \mathrm{C}$. 


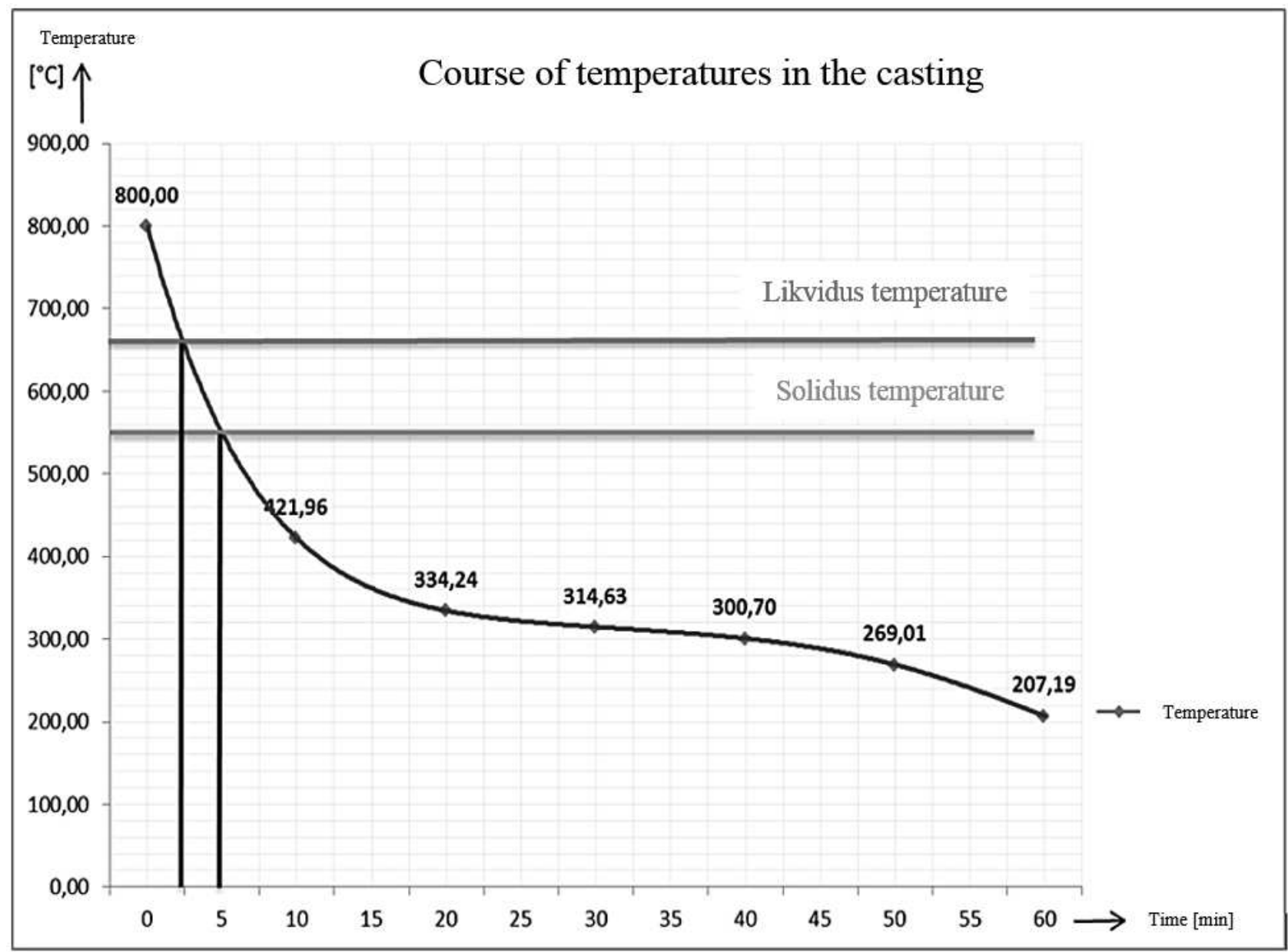

Fig. 13 Course of casting temperatures in the course of one hour

After two and a half minutes of free cooling of the alloy in the mould, the process of heterogeneous nucleation begins in the casting, which means that nuclei begin to form on foreign elements in the melt or on the solid phase particles. The nucleation process depends on the specific energy of a newly emerging phase interface. During the formation of nuclei, a sur- face is formed between the individual phases. Heterogeneous nucleation facilitates the crystallization process. Nucleation occurs on the mould walls even with relatively little cooldown. If the interface of newly formed crystals shows a smooth course of atomic planes, it is a coherent interface Fig. 14a. If the planes of the nucleus are not continuous with the planes of the catalyst, then it is an incoherent interface Fig. 14c [3].

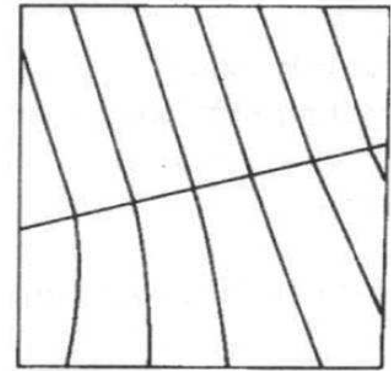

a)

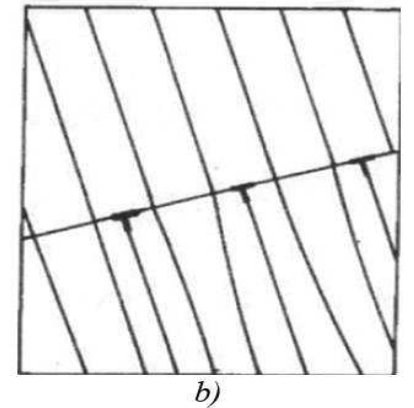

Fig. 14 Interface: coherent (a), semicoherent (b), incoherent (c)

If the nuclei are thermodynamically stable, the growth of crystals on them starts immediately. These crystals do not grow evenly, but in certain crystallographic directions, where primary, secondary and tertiary axes are formed. Such crystal growth results in the formation of dendrite. The direction and rate of crystal growth depends on the rate of cooling down and on the content of insoluble and soluble elements in the alloy. At high cooling rates, a fine-grained structure is formed, at slow cooling, the grain is coarse 
and globulite is formed. If more heat is conducted away from the mould in one direction, an oriented grain is formed. This process lasts up to the temperature of $550^{\circ} \mathrm{C}$

\section{Conclusion}

The paper describes the process of cooling an aluminium alloy casting after casting into an ingot mould. The course of cooling was modelled in the ANSYS FLUENT program. The performed numerical calculation shows that under selected initial conditions the solidification of the piston casting starts at time $t=2.5$ min. Solidification is completed at time $t=5 \mathrm{~min}$., followed only by cooling of the piston and the mould. It is thus clear that when the casting and the mould are cooled, a considerable amount of heat is released to the surroundings. This heat is conducted away by the air.

In the series production, both mould and core are water-cooled which causes a significant increase in the solidification rate and the times are reduced to less than half of the periods referred to above. The casting is removed from the mould after about 120 seconds and then cooled freely in air. After removing the casting from the mould, the mould is closed and another casting is being cast. This process in the mass production means a large thermal stress in the foundry environment. Therefore, intensive ventilation and air conditioning are necessary in the foundry.

In the next step of the solution, the numerical solution to casting a piston into a steel mould will be extended by water cooling. The results obtained in this way can be compared with the results obtained in real conditions. For a deeper scrutiny, it would be appropriate to change the cooling intensity and thus also the solidification time.

The aim of this article was to get acquainted with the foundry process. Description of the solidification process of the theoretical alloy in the mold on a model solution using the program ANSYS-Fluent. This is a simulation, not a practical example. The aim of the work was met.

\section{References}

[1] MICHNA, S., NOVA, I. (2008). Technology and processing of metal materials, Adin, s.r.o., Presov, $326 \mathrm{p}$.

[2] BOLIBRUCHOVA, D., TILLOVA, E. (2005). Al-Si Foundry alloys, University of Zilina, $180 \mathrm{p}$.
[3] PTACEK, L. A KOLEKTIV (2003). Material science I, Academic Publishing house CERM s.r.o., Brno, 516 p.

[4] MICHNA, S., TRPCEVSKA, J., NOVA, I. (2012). Engineering technology, FVTM UJEP, Usti nad Labem, $337 \mathrm{p}$.

[5] MICHNA, S., LUKAC, I., OCENASEK, V. A KOL. (2005). Encyclopedia of aluminium, Adin, s.r.o., Presov, 700 p.

[6] OTAHAL, V. Casting defects, defect atlas, ferrous and non-ferrous alloys, Technical and economic consultacy, MetalCasting and Foundry Consult, Brno, 40 p.

[7] BENCA, S. (2006). Computattional procedures of the MLP, Slovak university of Technology in Bratislava, Bratislava, $150 \mathrm{p}$.

[8] CSN 421240 Defect of casting. Nomenscluture and classification of defects.

[9] http://old.vscht.cz/met/stranky/vyuka/labcv/labor/fm_slevarenstvi/index.htm

[10] http://www.eurotechgroup.eu/cz/home

[11] KS Kolbenschmidt - internal records

[12] KOLNEROVA M, SOBOTKA J., KORECEK D., SOLFRONK P. (2019). Influence of Heat Treatment on the Change of AlSi Coating Properties at Ultra-high Strength Sheets, Manufacturing Technology, vol. 19, pp. 7781, 2019.

[13] HREN I., SVOBODOVA J., MICHNA S. (2019). Analysis of Microstructure Changes for AlSi7Mg0.3 Alloy Caused by Modification, $M a$ nufacturing Technology, vol. 19, pp. 767-71, 2019.

[14] SAPIETA, M., ŠULKA, P., SVOBODA M. (2018). Monitoring the fatique crack on the test specimen during the cyclic loading. MATEC Web of Conferences 157, 01016 (2018) doi.org/10.1051/matecconf/201815701016

[15] KUCHARIKOVÁ L., TILLOVÁ E., PASTIRČÁK R., UHRÍČIK M., MEDVECKÁ M. (2019). Effect of Wall Thickness on the Quality of Casts from Secondary Aluminium Alloy, Manufacturing Technology, vol. 19, pp. 797-801, 2019. 